\title{
Fallot Pentalojisi'nin eşlik ettiği Dandy-Walker varyasyonu: Olgu sunumu
}

\author{
Dandy-Walker variant associated with pentalogy of fallot: Case report
}

\author{
Ahmet Sami Güven*, Mehmet Burhan Oflaz, Ali Kaya, Fatih Bolat, Osman \\ Gülsever, İsmail Şalk, Özlem Bozoklu Akkar, Füsun Dilara İçağasıoğlu
}

Çoçuk Nöroloji Bilim Dalı (Yrd. Doç. Dr. A. S. Güven, Prof. Dr. F. D. İçağasıoğlu), Çocuk Kardiyoloji Bilim Dalı (Doç. Dr. M. B. Oflaz), Çocuk Sağlığı ve Hastalıkları Anabilim Dalı (Doç. Dr. A. Kaya, Doç. Dr. F. Bolat, Araş. Gör. Dr. O. Gülsever), Radyoloji Anabilim Dalı (Yrd. Doç. Dr. İ. Şalk), Kadın Hastalıkları ve Doğum Anabilim Dalı (Yrd. Doç. Dr. Özlem Bozoklu Akkar), Cumhuriyet Üniversitesi Tıp Fakültesi, TR-58140 Sivas

\section{Özet}

Dandy-Walker varyasyonu, 4. ventrikül ve sisterna magna arasındaki devamlılıkla sonuçlanan vermisin parsiyel agenezisi ile karakterize santral sinir sisteminin nadir bir anomalisidir. Literatürde ilk kez 1988'de Kohyama ve ark. [10] tarafından bildirilen Dandy-Walker varyasyonu ve Fallot Tetralojisi birlikteliği daha sonraki yıllarda birkaç vaka sunumu şeklinde bildirilmiştir. Biz bu yazıda, Dandy-Walker varyasyonu ve Fallot Pentalojisi olan 2 günlük bir erkek hastayı bildiriyoruz.

Anahtar sözcükler: Dandy-Walker varyasyonu, Fallot Pentalojisi

\begin{abstract}
Dandy-Walker variant is a rare anomaly of the central nervous system that is characterized by partial agenesis of vermis and results in persistence of the 4. ventricule and cisterna magna. Firstly, in 1988 Kohyama et al. [10] reported the coexistence of Dandy-Walker variant and tetralogy of Fallot. Afterwards, it is reported as several case reports in the literature. In this case report, we report a 2 days-old male patient with Dandy-Walker variant and pentalogy of Fallot.
\end{abstract}

Keywords: Dandy-Walker variant, pentalogy of Fallot

Geliş tarihi/Received: 09 Haziran 2014; Kabul tarihi/Accepted: 23 Temmuz 2014

*İletişim adresi:

Dr. Ahmet Sami Güven, Çocuk Nöroloji Bilim Dalı, Cumhuriyet Üniversitesi Tıp Fakültesi, TR-58140 Sivas. E-posta: asamiguven@ hotmail.com

*Bu makale XV. Ulusal Çocuk Nörolojisi Kongresi’nde poster olarak sunulmuştur.

\section{Giriş}

Dandy-Walker malformasyonu (DWM), serebellumun en s1k konjenital malformasyonu olup insidansı 1/5000 canlı doğumdur [1]. Dandy-Walker varyasyonu, 4. ventrikül ve sisterna magna arasındaki devamlılıkla sonuçlanan vermisin parsiyel agenezisi ile karakterize DWM'nunun bir formudur [2].

Biz bu yazıda yenidoğan döneminde Dandy-Walker varyasyonuna eşlik eden Fallot Pentalojisi tespit edilen erkek hastayı nadir görülen bir birliktelik olması nedeniyle sunmak istedik. 


\section{Olgu sunumu}

Otuz üç yaşındaki anneden 38 haftalık olarak sezeryan ile 2000 gram olarak doğan bebeğin intrauterin ultrasonografisinde Dandy-Walker varyasyonu ve gelişme geriliği saptanmış ve doğum sonrası hastanemize sevk edilmişti. Bebeğin fizik muayenesinde; vücut ağırlığı: $2000 \mathrm{~g}(<3 \mathrm{p})$, boy: $41 \mathrm{~cm}(<3 \mathrm{p})$, baş çevresi: $33 \mathrm{~cm}(3-50 \mathrm{p})$, geniş burun kökü, bilateral simian çizgisi, yüksek damak, nabız oksimetre ile saturasyonu $\% 89$, sternum solu 2. interkostal aralıkta duyulan $3 / 6^{\circ}$ pansistolik üfürümü dışında diğer muayeneleri doğal idi. Laboratuar tetkiklerinde hemogram, biyokimya, TORCH paneli, tiroid fonksiyon testleri normal sınırlarda olan hastanın kromozom analizi normal erkek karyotip (46, XY) ile uyumlu idi. Doğum sonrası yapılan beyin manyetik rezonans incelemesinde Dandy-Walker varyasyonu izlenen (Resim 1) hastanın ekokardiyografik incelemede sağ ventrikül hipertrofisi, geniş subaortik ventriküler septal defekt, aortada dekstrapozisyon, valvüler ve infundibuler pulmoner stenoz ve ilave küçük sekundum atriyalseptal defekt tespit edildi ve bu bulgular Fallot Pentalojisi ile uyumlu idi (Resim 2). İlave anomaliler açısından yapılan tetkiklerinde ek anomali tespit edilmedi.
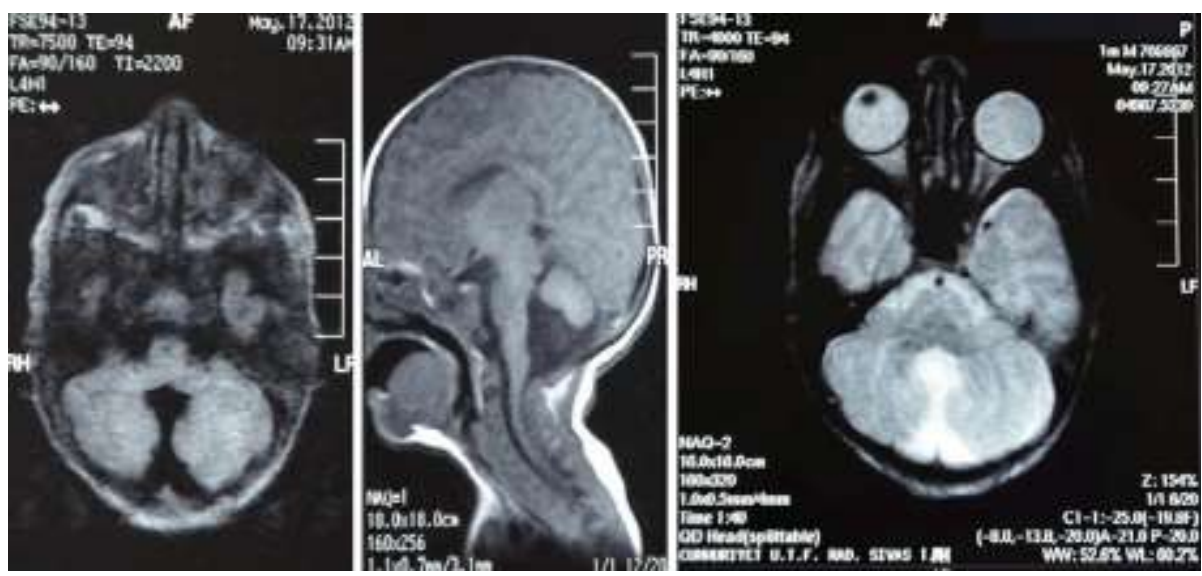

Resim 1. Olgumuzun beyin manyetik rezonans görüntülemesinde Dandy-Walker varyasyonu, 1A. Aksiyal T1, 1B. Sagittal, 1C. Aksiyal T2 görüntüsü.

\section{Tartışma}

DWM, 1887'de Sutton tarafindan tanımlanmış, 1914'de Dandy ve Blackfan ve 1942'de Tagart ve Walker tarafindan karakterize edilmiştir [3]. Embriyogenez sırasında 4. ventrikül tepe kısmının gelişimsel yetersizliği sonucu ortaya çıkan Dandy-Walker kompleksi birkaç varyantı içerir [1-4].

Dandy-Walker malformasyonu: Posterior fossada genişleme, serebellar vermisin komplet veya parsiyel agenezisi, 4. ventrikülün kistik dilatasyonu.

Dandy-Walker varyasyonu: Posterior fossada genişleme olmaksızın 4. ventrikül ve sisterna magna arasındaki devamlılıkla sonuçlanan vermisin parsiyel agenezisi.

Mega sisterna magna varyasyonu: Serebellar vermis ve 4. ventrikülün normal olduğu sisterna magna genişlemesi ile karakterizedir.

DWM'de, kısa boyun, mikrosefali, brakisefali, hipertelorizm, antimongoloid palpebral fissür, yüksek damak, yarık damak, klinodaktili gibi dismorfik bulgular ve kusma, uyuklama, irritabilite, konvülziyon, dengesizlik, hipotoni, psikomotor gerilik, strabismus ve myopi gibi klinik bulgular görülebilir [1,3]. Olgumuzun da intrauterin gelişme geriliği ile birlikte geniş burun kökü, bilateral simian çizgisi, yüksek damak gibi dismorfik bulguları var idi. 
DWM'lu olguların yaklaşık yarısında kardiyak anomaliler [ventriküler septal defekt (VSD), patent duktus arteriosus (PDA), büyük arterlerin transpozisyonu], ürogenital anomaliler (hidrosel, vesiko üreterel reflü) ve diğer anomaliler (duedonal atrezi, yarık damak, ekstremite malformasyonları) gibi sistemik malformasyonlar eşlik etmektedir [1]. Sasaki-Adams ve ark. [5] Dandy-Walker varyasyonu olan 24 çocuk hastada ek anomalileri değerlendirmişler ve en sık eşlik eden anomalinin kardiyak anomaliler $(\% 41,7)$ olduğunu bildirmişlerdir. Olgumuzda Fallot Pentalojisi dışında ek anomali tespit edemedik.

PHACE sendromu (posterior fossa malformasyonlar1, hemanjiomlar, arteriyal anomaliler, aort koarktasyonu ve kardiyak defektler ve göz anormallikleri) [6] ve Ritscher-Schinzel (kraniyofasiyal, serebellar, kardiyak, 3C) sendromu [7] DWM' nunun eşlik ettiği sendromlardır. Olgumuzda hemanjiomlar, arteriyel anomaliler ve göz anormalliklerinin olmaması ile PHACE sendromu ile uyumlu değildi. Ritscher-Schinzel sendromunun (3C sendromu) kardiyak ve serebellar bulguları DWM ile benzer olup kraniyofasiyal bulguları (oküler koloboma, belirgin oksiput, düşük kulaklar, hipertelorizm, aşağı yönlü palpebral fissür, deprese burun kökü, mikrognatti) DWM'dan farklıdır. Olgumuzda geniş burun kökü, bilateral simian çizgisi, yüksek damak gibi dismorfik bulguları olmakla birlikte $3 \mathrm{C}$ sendromu ile uyumlu değildi ve göz bulguları da yoktu.

Hsieh ve ark. [8] intrauterin dönemde DWM ile birlikte konjenital kalp hastalığı (pulmoner atrezili VSD ve overriding aorta) tespit ettikileri bir olgunun amniyon sıvısından yapılan genetik analizinde non-mozaik trizomi 20 olduğunu tespit etmişlerdir. Literatürde Hsieh ve ark.' nın bildirdikleri DWM ve konjenital kalp hastalığı birlikteliği bulunan olgu dişında kromozom anomalisi olan hasta bildirilmemiştir. Bizim olgumuzun da karyotip tayini normal idi.

Hirsch ve ark. [9] DWM'nuna kraniyofasiyal ve kardiyovasküler malformasyonların eşlik ettiğini ve bu durumun postovulatuar 4. haftadan sonra ortaya çıkan bir durum olduğunu bildirmişlerdir. DWM ile Fallot Tetralojisi birlikteliği ilk kez 1988 yılında Kohyama ve ark. [10] tarafından bildirilmiştir. Özdemir ve ark. [4] Dandy-Walker varyasyonuna eşlik eden ASD'li Fallot Tetralojisi, PDA ve primer hipotiroidisi olan 11 aylık bir olguyu bildirmişlerdir. Literatürde Özdemir ve ark.'nın bildirdikleri olgu dışında DWM'na eşlik eden Fallot Pantalojisi şimdiye kadar bildirilmemiştir. Olgumuz, Türkiye'den bildirilen 2. olgu olup Özdemir ve ark.'nın bildirdikleri olgudan farklı olarak olgumuzda PDA ve primer hipotiroidi yoktu ve yenidoğan döneminde tanı almış idi.

Sonuç olarak; DW anomalileri tespit edilen olgularda kardiyak malformasyonların eşlik edebileceğinin akılda tutulması ve hastaların bu açıdan dikkatli bir şekilde tetkik edilmesinin uygun olacağını vurgulamak istedik.

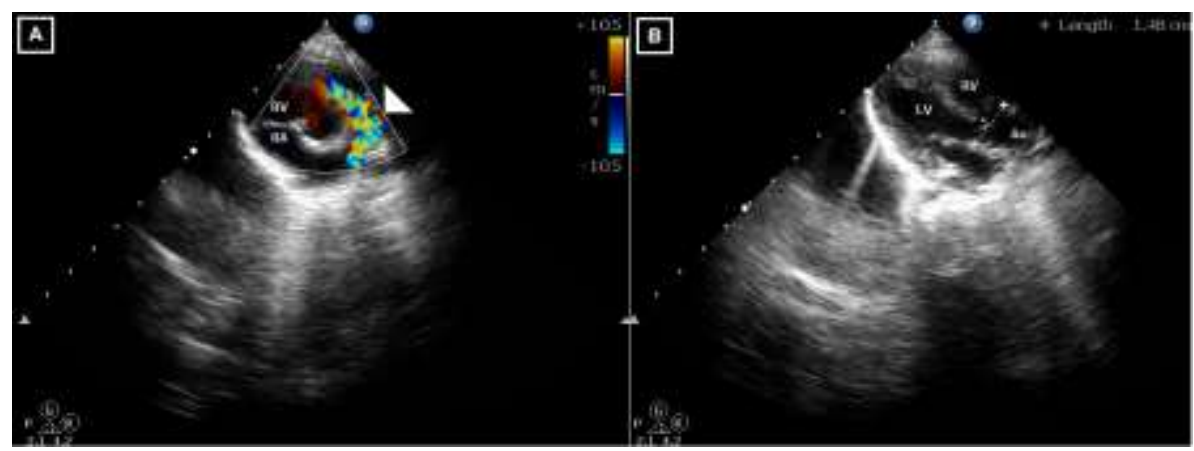

Resim 2. Parasternal kısa eksen görüntülemede infundibuler ve valvüler düzeyde darlık imajı gösteren renkli Doppler görüntüsü (A). İnterventriküler septumun üst kısmında (yıldız) geniş malalignment ventriküler septal defekt ve aortanın dektrapozisyonu görülüyor (B). RV, sağ ventrikül; $L V$, sol ventrikül; Ao, aorta. 


\section{Referanslar}

1. Millen KJ, Gleeson JG. Disorders of Cerebellar and Brainstem Development. In: Swaiman KF, Ashwal S, Ferriero DM, Schor NF, eds. Swaiman's Pediatric neurology: principles and practice. 5th ed. Philadelphia: Elsevier Saunders 2012; $160-5$.

2. Barkovich AJ. Congenital Malformations of the Brain and Skull. Pediatric Neuroimaging. 4th ed. Philadelphia: Lippincott Williams\&Wilkins 2005; 387-91.

3. Tadakamadla J, Kumar S, Mamatha GP. Dandy-Walker malformation: An incidental finding. Indian J Hum Genet 2010; 16: 33-5.

4. Ozdemir O, Polat A, Cinbis M, Kurt F, Kucuktasci K, Kiroglu Y. DandyWalker's variant and tetralogy of Fallot with atrial septal defect and patent ductus arteriosus and primary hypothyroidy--a new association. Indian J Pediatr 2009; 76: 433-5.

5. Sasaki-Adams D, Elbabaa SK, Jewells V, Carter L, Campbell JW, Ritter AM. The Dandy-Walker variant: A case series of 24 pediatric patients and evaluation of associated anomalies, incidence of hydrocephalus, and developmental outcomes. J Neurosurg Pediatr 2008; 2: 194-9.

6. Poetke M, Frommeld T, Berlien HP. PHACE syndrome: new views on diagnostic criteria. Eur J Pediatr Surg 2002; 12: 366-74.

7. Leonardi ML, Pai GS, Wilkes B, Lebel RR. Ritscher-Schinzel cranio-cerebellocardiac (3C) syndrome: report of four new cases and review. Am J Med Genet 2001; 102: 237-42.

8. Hsieh CC, Hsu JJ, Lo LM, Hsieh TT, Soong YK. Non-mosaic trisomy 20 in cultures of amniotic fluid from a fetus with serious congenitale malformation. $\mathrm{J}$ Formos Med Assoc 1992; 91: 543-4.

9. Hirsch JF, Kahn AP, Renier D, Rose CS, Hirsch EH. The Dandy-Walker malformation. J Neurosurg 1984; 61: 515-22.

10. Kohyama J, Watanabe S, Iwakawa Y, Fukuda C. A case of Dandy-Walker malformation: consideration on the teratogenic period and sleep structures. Brain Dev 1988; 10: 392-6. 